\title{
FIELDWORK ROBOT- MONITOR AND PERFORM AGRICULTURAL TASKS
}

\author{
Thilagavathy $\mathrm{R}$ \\ Assistant professor \\ Department of ECE \\ GSSSIETW, Mysuru, Karnataka, India
}

\begin{abstract}
In the proposed system we are designing a robot to perform an agriculture tasks and monitor the storage area. India population is about $17.7 \%$ of the total world population. India is second most populated country in the world. According to food and agriculture organization (FAO) India's $70 \%$ of rural households still depend primarily on agriculture for their livelihood. Nowadays, millions of farmers leaving farming and villages in search of better opportunities in cities because of agricultural problems like more labor wages, wastage of seeds during seeding, theft in storage areas, lack of irrigation, more time requirement for every operations, lower yield of crops and so on. We are designing a system to overcome all these problems. In our proposed system, we are using HC-06 Bluetooth module for controlling the robot. The proposed robot can perform the tasks like ploughing the land using position feedback servo motor, seeding using DC motor and relay, irrigation using submersible pump and along with one of the special task like intruder monitoring using PIR sensor and GSM module. Intruder monitoring is performed automatically using line sensors.
\end{abstract}

Keywords - Bluetooth, DC motor, GSM module, PIR sensor, Relay, Servo motor, submersible pump.

\section{INTRODUCTION}

India is an agrarian economies among many countries in Asia and the livelihood of many rural populations are depends on agriculture. Nowadays farmers contribute a sufficient amount of cash on tools that support them to cut back labor performance and expansion of yield of crops. A quite impressive record of progress in agriculture has been achieved in India over the past four decades. The agriculture sector has been successful keep up with rising demand for food. The contribution of increased acreage under agricultural production has declined over time and increases in production within the past 20 years are almost entirely due to increased productivity. Agriculture can increase the productivity to feed the poor, boost farm income and provide opportunities for employment. The overall progress of contribution of agricultural growth has been widespread. The success of India's agriculture is attributed to a series of steps that led to availability of farm technologies which caused dramatic

\author{
Yashaswini H P \\ Student \\ Department of ECE \\ GSSSIETW, Mysuru, Karnataka, India
}

increases in productivity in $70 \mathrm{~s}$ and $80 \mathrm{~s}$ often described because the revolution era [1]. Future growth must be more rapid, more cosmopolitan and better targeted.

These challenges have profound implications for the way farmers' problems are conceived, researched and transferred to the farmers. "On the one hand agricultural research will increasingly be required to deal with location specific problems facing the communities on the opposite the systems will need to position themselves in an increasingly competitive environment to get and adopt leading edge technologies in touch upon the solutions facing a huge majority of resource poor farmers". The robotic systems play an immense role in all sections of societies, organization and industrial units.

The WHO assess that, Earth's populations will be probably 9 billion in 35 years which will dominant to a shocking persistence in increase of development of food crops. The best solution is automation to occupy all the shortcomings by initiating measures that yield more crops [2].

The robot starts its task by ploughing the field and sows the seeds simultaneously then it starts the irrigation after completion of the ploughing and seeding operation. It uses basic components like DC motors, servo motor, relay and pump as the main controller. The mechanical design of the robot is additionally simple. It is programmed to carry out the above functions simultaneously. To perform the function of ploughing it's equipped with spiked wheels which are fixed within the anterior end of the robot, to sow seeds it's a container with seeds and its bottom contains a perforation to drop the seed and eventually the posterior end of the robot. Later the irrigation of the seed takes place by using the submersible pump. One of the important features added in our system is intruder monitoring. PIR (passive infrared sensor) used in this monitoring system it will sense the heat energy emitting body like human and animals then send the message via a sim800 GSM model to the former. One of the number has been initially saved in the model for whom the message have to be sent for that number the alert message has been send. 


\section{RELATED WORK}

Farming is growing crops or keeping animals by people for food and raw materials. Farming is a part of agriculture. Along with the farming it checks the soil ph, temperature, moisture, humidity [1]. Here camera is used for live streaming but the solenoid is used to control seeding and fertilizing, system is complex and more space required. Amrita Sneha [2], aims to perform automated ploughing and simultaneous seeding process using Advanced Virtual RISC (AVR), but outside the field is strictly operated in manual mode. The robot starts its function by ploughing the field, then sows the seeds in the ploughed area and ends the process with covering the seeds sown with soil [3],[4]. It minimizes the labor of farmers and increases the speed but Low efficiency and accuracy. In this proposed system [5] robot is controlled by a human operator who manually guides the robot through a desired path called teaching phase, then robot will navigate autonomously with taught information called execution phase. It translates demonstrated behaviour immediately into executable code but counter variable can overflow any time. Here brain computer interface system is used [6], which does not require training for individual users but it require excessive training for proper usage, slow speed. Swati D. Sambare [7], aims to drop seeds at particular position with specified distance between two seeds but complex design for single operation. Mark E. Russell [8], proposed a universal gripping mechanism, which should possess the ability to pick unfamiliar objects irrespective of its shape within the given size range, but it increases the complexities on both hardware and software for smaller objects. Rabiulhossenrafi [9], effective system for irrigation system using line follower robot but, moisture sensor is not used, same amount of water is provided to all type of plants. Lijina. P Nippun [10], in a proposed collision avoidance variable speed technique based on the RSSI value of robots is used and the obstacle avoidance is implemented, but proximity sensors have a limited operating rage. Saurabh Umarkar [11], proposed a system farming is powered by solar panel with a control of Android Application, but solar panels is high cost. This system automatically detecting the symptoms of Powderly mildew [12], a major fungal grapevine disease and selectively spraying diseased canopy areas, but Cycle time was one of the major issues. T AMohanaprakash [13], aims in making agriculture smart using robotics and IoT technologies. Pirkala Athish Reddy [14], RF remote controls the tractors during farming, but it can be used only for shorter distance. Agricultural farming robot which can move instinctively, involuntarily for ploughing in different depths depending upon soil [15], seeding and irrigation in adjacent field. The agricultural Robot equipped with the camera and sends the data to pc through Wi-Fi network.

\section{PROPOSED SYSTEM}

The Field Robot works with the battery. The Field Robot requires $12 \mathrm{~V}$ battery to operate the system as L293D motor driver is used. The model consists of 4 wheels which are connected to four DC motors respectively, both left motors are shorted and right motors are also shorted, wheels are driven by L293D motor driver. On the front end of the chassis cultivator is used which is connected to servo motor which is made to dig the soil. The seeds are dropped through funnel as the shaft rotates. A water pump sprayer is used for spray the water or pesticides. Field Robot also performs the unique function i.e., intruder monitoring. Bluetooth technology is used to control the entire operation of robot through smart phone for ploughing, seeding and pesticides spraying systems. The Heart of the proposed system includes Arduino Uno. Bluetooth module, DC motors, GSM module, relay and motor driver are interfaced to Arduino Uno. Bluetooth technology enables the Field Robot to move in four directions i.e., front, back, right and left. Various commands are used to move the Field Robot into forward, reverse, stop, left, and right and to perform various functions in the field according to the commands received.

\section{A. Hardware Requirements}

The Hardware requirement for the system is as follows:

\section{Arduino UNO}

The Arduino UNO [19] is an open-source microcontroller board supported the Microchip ATmega328P microcontroller and developed by Arduino fashion as shown in figure 2.The board has 14 Digital pins, 6 analog pins, and programmable with the Arduino IDE (Integrated Development Environment) via a sort B USB cable. It accepts voltages between 7 and 20 volts. The ATmega328 on the Arduino Uno comes preprogrammed with a boot loader that permits uploading new code thereto without the utilization of an external hardware programmer.

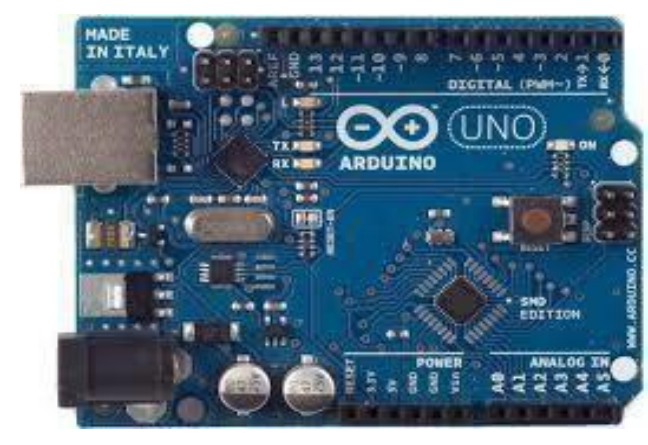

Figure 1. Arduino UNO 


\section{Ultrasonic Sensor}

An ultrasonic sensor is an instrument that measures the space to an object using ultrasonic sound waves fashion as shown in figure 2. An ultrasonic sensor uses a transducer.

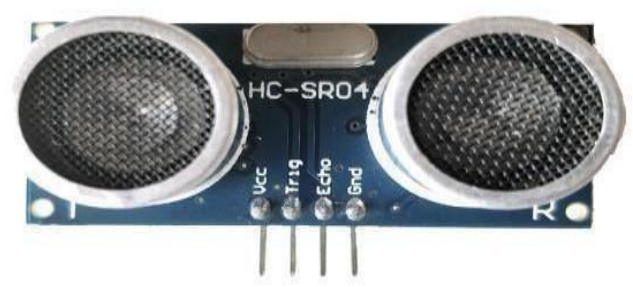

Figure 2. Ultrasonic sensor

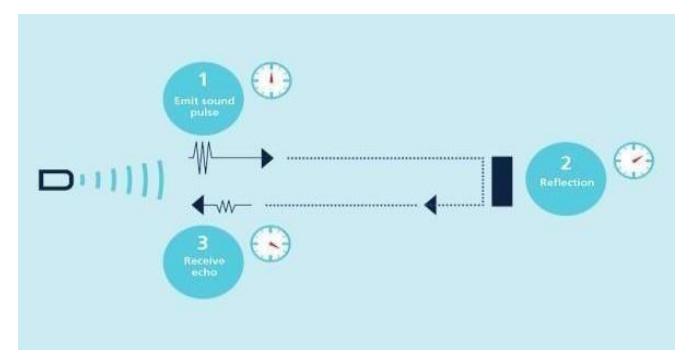

Figure 3. Working principle of Ultrasonic sensor

To send and receive ultrasonic pulses that relay back information about an object's proximity. High-frequency sound waves reflect from boundaries to provide distinct echo patterns. The working principle is as shown in figure 3 .

\section{Servo motor}

Servomotors are used for seeding mechanism (it can address a specified position). A servomotor may be a positioner or linear actuator that permits for precise control of angular or linear position, velocity and acceleration. It consists of an appropriate motor coupled to a sensor for position feedback. It also requires a comparatively sophisticated controller, often a fanatical module designed specifically to be used with servomotors

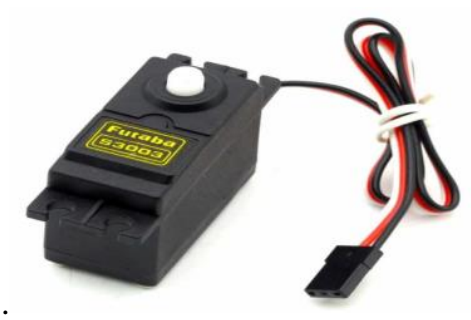

Figure 4. Servo motor

Servomotors aren't a selected class of motor although the term servomotor is usually wont to ask a motor suitable to be used during a closed-loop system . Servomotors are used in applications such as robotics, Computerized Numerical Control (CNC) machinery or automated manufacturing.

\section{Bluetooth $\mathrm{HC}-05$}

HC-05 module is a simple to use Bluetooth interface Protocol module (SPP), designed for transparent wireless serial connection setup. The HC-05 Bluetooth Module are often utilized in a Master or Slave configuration, making it an excellent solution for wireless communication. This interface Bluetooth module is fully qualified Bluetooth V2.0+EDR (Enhanced Data Rate) 3Mbps Modulation with complete $2.4 \mathrm{GHz}$ radio transceiver and baseband.

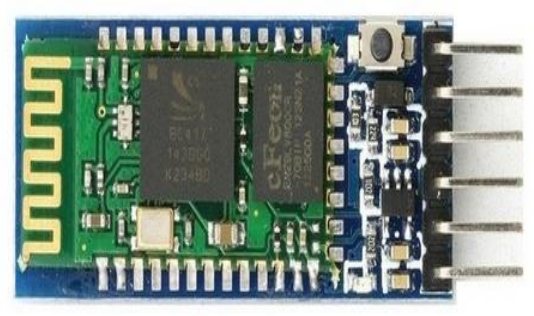

Figure 5. Bluetooth module HC-05.

It uses Cambridge Silicon Radio (CSR) Blue core 04 External single chip Bluetooth system with Complementary MetalOxide Semiconductor (CMOS) technology and with Adaptive Frequency Hopping Feature (AFH).

\section{PIR (passive infrared sensor):}

PIR Sensor "Passive Infrared Sensor" reacts to the natural process (heat energy) caused by the movement of physical body. It requires an unobstructed line-of-sight for accurate detection, if there's an obstruction, like furniture or partition between the person and therefore the detector, the person can't be detected. generally, PIR sensor responds to larger movements (i.e., walking) and is a smaller amount influenced by the air flow interruption which makes it works optimally within the spaces with high air flow and frequent occupant's movement but without having high ambient temperature.

The PIR sensor itself has two slots in it, each slot is formed of a special material that's sensitive to IR. The lens used here isn't really doing much then we see that the 2 slots can 'see' out past a long way (basically the sensitivity of the sensor). When the sensor is idle, both slots detect an equivalent amount of IR, the ambient amount radiated from the space or walls or outdoors. 


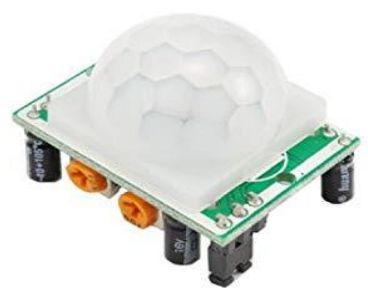

Figure 6. PIR Sensor.

\section{GSM module}

GSM could even be a mobile communication modem; it's stands for global system for mobile communication (GSM). the thought of GSM was developed at Bell Laboratories in 1970. it's widely used mobile communication system within the earth. GSM is an open and digital cellular technology used for transmitting mobile voice and data services operates at the $850 \mathrm{MHz}, 900 \mathrm{MHz}, 1800 \mathrm{MHz}$ and $1900 \mathrm{MHz}$ frequency bands. GSM system was developed as a digital system using Time Division Multiple Access (TDMA) technique for communication purpose.

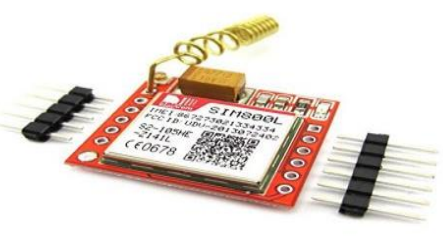

Figure 7. SIM800L GSM module

A GSM digitizes and reduces the info, then sends it down through a channel with two different streams of client data, each in its own particular slot. The digital system has a capability to hold $64 \mathrm{kbps}$ to $120 \mathrm{Mbps}$ of knowledge rates. Subscriber Identity Module (SIM) 800L series GSM modules have a inbuilt Bluetooth stack compliant with 3.0+EDR \& FM radio support, and the interface is accessible using AT commands. SIM800C GSM module comes in a very compact size of $17.6^{*} 15.7 * 2.3 \mathrm{~mm}$ dimensions compared to SIM900/SIM800 which comes in $24 * 24 * 3 \mathrm{~mm}$ package. SIM800L GSM module comes in a similar small size as SIM800C but with FM functionality instead of Bluetooth.

\section{B. Software Requirements}

ATMEGA328 microcontroller is used to control the various operations of proposed system. Bluetooth model is used to control ploughing, seeding, pesticides spraying and intruder monitoring. left motors and right motors of wheels are connected to 2,3,4 and 5th of digital output pins of Arduino through motor driver L293D.Servo motor for ploughing purpose is connected to 9th digital output pin of Arduino through sugar cube relay. For Pesticides spraying, the sugar cube relay is connected to 10th digital output pin of Arduino. Similarly for seeding functions, other sugar cube relay is used which is connected to 11th digital output pin through it. The intruder monitoring function is achieved using GSM model which is in turn connected to 7 and 8th digital pins of Arduino (one pin for transmitting another for receiving the signals), PIR Sensor is connected to the 6th digital pin of arduino which detects the intruder entering the field premises. Bluetooth module HC-06 is used to control the above operations through BLUETOOTH APP.

Bluetooth module is operated through the Bluetooth app. Initially the module must be paired to smart phone to perform operations. Once the establishment of the connection is done then the app will show the connection status. The nine commands are stored using the set keys option as F (forward), B (backward), L (left), R(Right), P (Ploughing), S (Seeding), Q (Pesticides spraying), I (Intruder Monitoring), 1 (to stop Ploughing and Seeding), 2 (to stop Water spraying) and 3(to stop intruder monitoring), 4 (to stop all the functions of the robot). According to the given commands and program dumped into the microcontroller the Field Robot will move and performs above functions.

The flow chart for the Prototype model is shown in figure. 2, developed in 2 phases, i.e., hardware and software. The hardware design deals with interfacing Bluetooth module, DC motors, Ploughing system through motor driver, seeding and pesticides spraying system through sugar cube relay and intruder monitoring system to microcontroller of Arduino. 


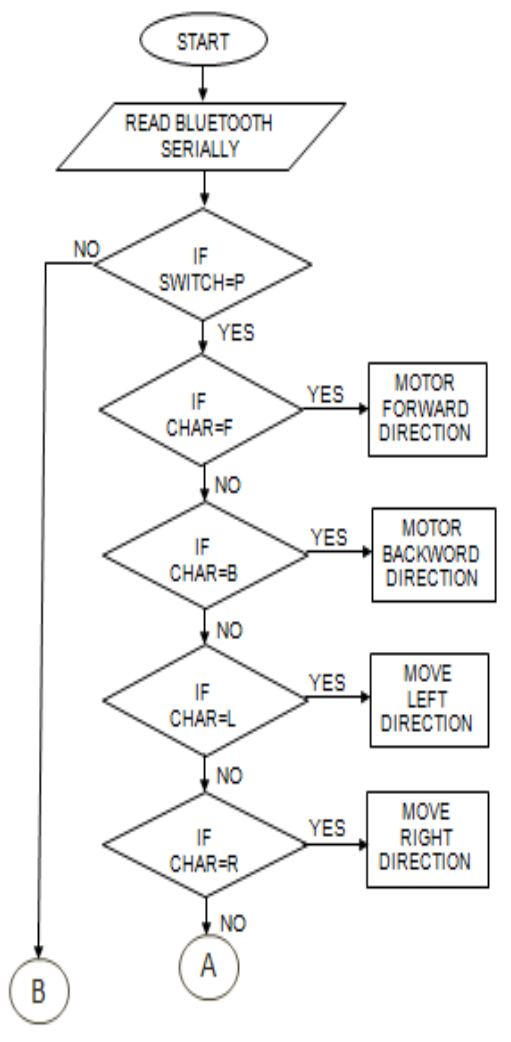

IV. DESIGN AND IMPLEMENTATION

The system is designed and developed to perform the multi functions i.e., ploughing, seed sowing, pesticides spraying, in addition to this it does intruder monitoring through Bluetooth APP which controls the functions of the Field Robot accordingly. The various functions of a model are explained below:

\section{Ploughing function:}

The main purpose of the ploughing operation is to turn over the soils upper layer using ploughing arm as shown in fig 3 ., allowing the fresh nutrients to the surface. In the prototype model shown below, DC Motors is used for ploughing the farm. As the wheels which is connected to the dc motors rotates. Then the cultivating arm is lowered down and the soil is dug up to 1 inches. A servo motor with particularly angle of degree with proper timing helps the robot to do the operation. The direction of the cultivator can also be controlled by the Bluetooth app in the smart phone.

\section{Seed sowing function:}

Seeding function is planting seeds in a place followed by the ploughing function. In the prototype model shown fig. 2 , a box is used for storing the seeds and the shaft is connected to dc motor, as the motor rotates along with the shaft it drifts the seeds from the box, and drops to the soil through the funnel.

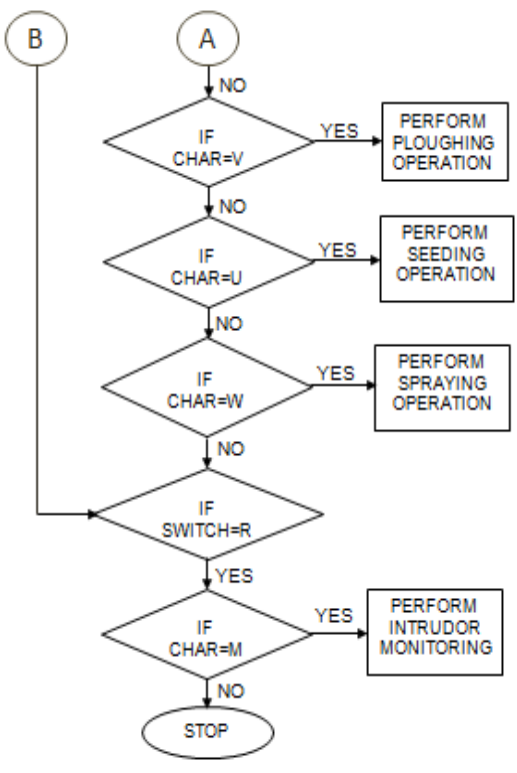

Figure 8. Flowchart for the proposed system.

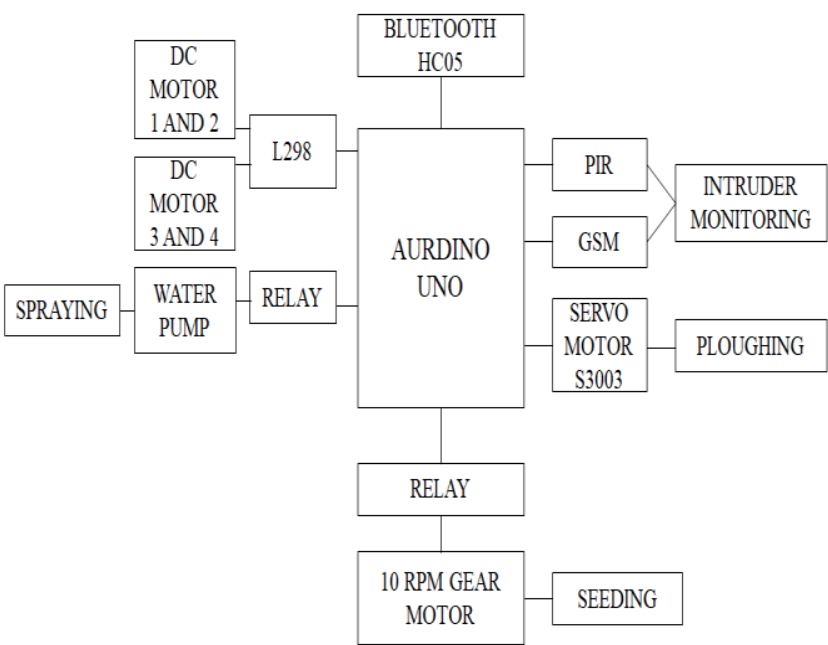

Figure 9. Block Diagram of Field Robot Automation Model.

\section{Pesticides spraying function:}

In this a submersible water pump is used to drift the water or fertilizers from the container, through water pipe the water is allowed to drop just after seed sowing operation is done. This model is either used for pesticides spraying after the crops grown up to keep them safe from getting affected by pesticides. 


\section{International Journal of Engineering Applied Sciences and Technology, 2020 \\ Vol. 5, Issue 4, ISSN No. 2455-2143, Pages 196-202 \\ Published Online August 2020 in IJEAST (http://www.ijeast.com)}

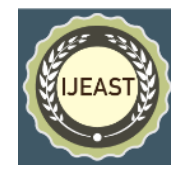

\section{$>$ Intruder monitoring function :}

The unique feature of this prototype model is to look over the crops from intruders. This feature is achieved by using PIR Sensor which detects the intruders by detecting the heat radiated by intruder or animal. After the detection, the SMS is send through the GSM model to the owner of the field.

The system consists of Arduino Uno which is based on ATmega328 micro controller as its brain. It is 8bit micro controller assuming on $16 \mathrm{MHz}$ clock speed. It has 23 programmable $\mathrm{I} / \mathrm{O}$ lines. It's powered on $5 \mathrm{~V}$ regulator which is connected to a $12 \mathrm{~V}$ lead acid battery. The digital pins are used to drive the L298 motor driver for controlling robots directions. The motor is supplied with $12 \mathrm{~V}$ lead acid battery. The user operated and controls different actions such as direction, movement switching, seeding motor and pump with a android app. The received data is decoded and programmed for acquired operation. It is supplied with $5 \mathrm{v}$ and ground. In order to turn pump and seeding mechanism a $5 \mathrm{v}$ SPDT relay is used to trigger $\mathrm{ON}$ or OFF. S3003 Servo motor is used for ploughing action. It requires $7 \mathrm{v}$ to run, hence a buck converter LM2596 is used to step down and with PWM pin its angle is controlled.

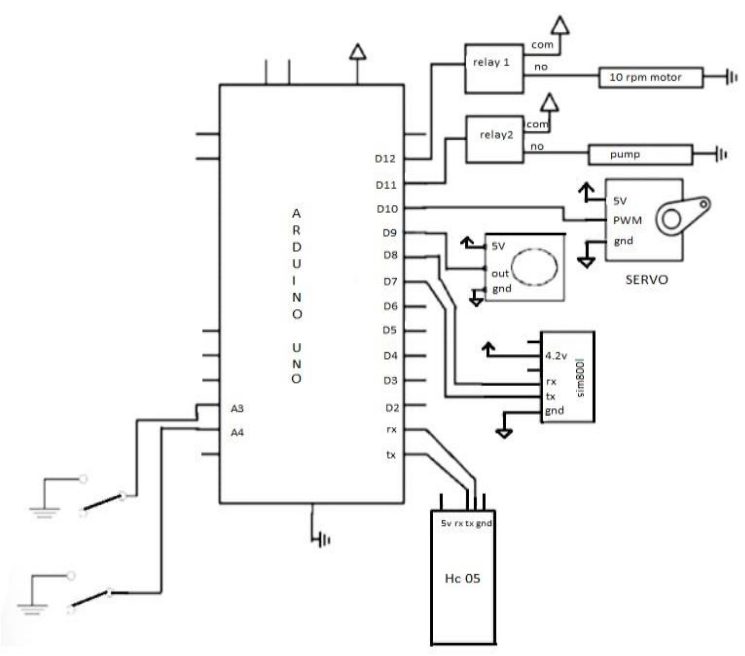

Figure 10. Detailed circuit diagram.

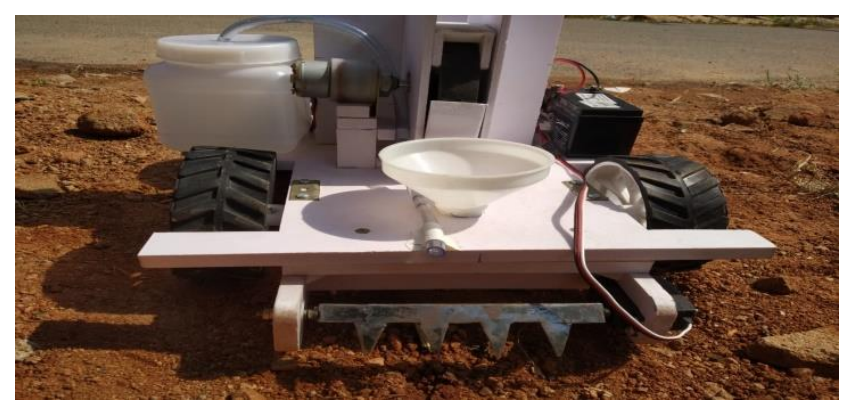

(a) Ploughing mechanism

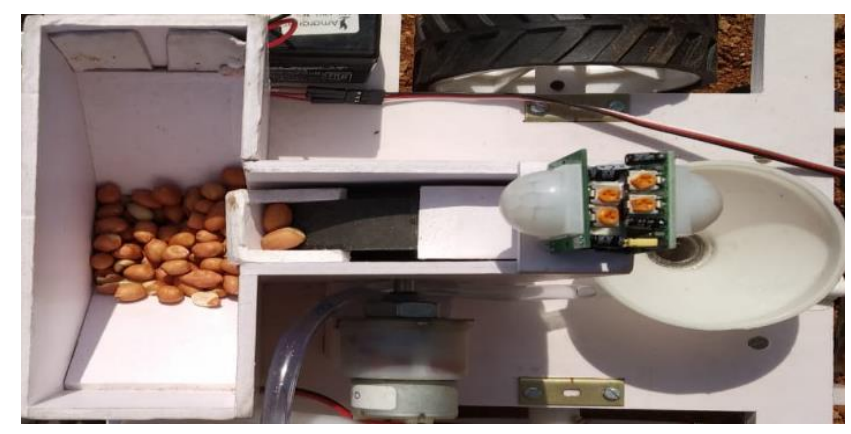

(b) Seeding mechanism

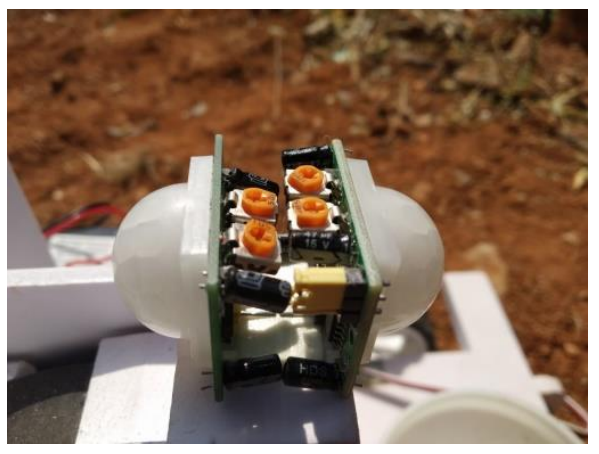

(c) Intruder monitoring by PIR

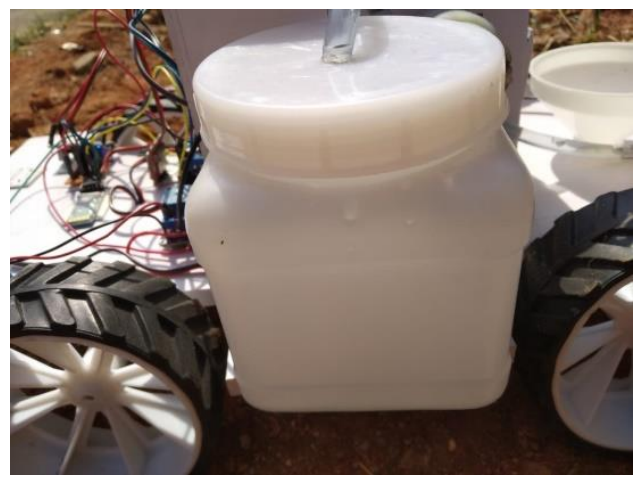

(d) Spraying tank

Figure 11. Implementation of Field Robot6

\section{CONCLUSION}

In this work, a robot has been designed, built and demonstrated to perform the tasks like moving and farming the field. This robot is implemented in ploughing the field, distribution of seeds, and pesticides spraying within the boundary and also implement as automated intruder monitoring. In agriculture by using the automated multipurpose agricultural robot we can easily reduce the former efforts and time. The machine requires less time and less man power compared to traditional method. 
In this way we can overcome the labors problems and also the monitoring of grain storage apart from seeding, irrigation, fertilization and intruder monitoring. Fruit picking, harvesting, weeding, etc. can also be implemented in this robot. And one or more system can be, monitoring through the image processing. In future we can use the IOT and real time data collection. We can also design agricultural based Agriculture Robots like Nursery bot, Herder bot, Wine bot, Bee bot, and Hamster bots that would qualify the standards from the current precision to autonomous farming methodologies. The moisture content, soil efficiency can be checked by equipping the robot with the suitable sensors to detect the specific level. The solar energy can be generated and used as a source of power for the functioning of the robot by attaching the solar panel to the device.

\section{REFERENCE}

[1] shivaprasad B S, Ravishankar M N, B N shoba, "design and implimentation of seeding and fertilyzing agriculture robot", international journal of application in engginering and management (IJAIEM), volume 3, issue 6, june 2014 ISSN 2319-4847.

[2] AmritaSneha.A, Abirami.E, Ankita.A, Mrs.R.Praveena, Mrs.R.Srimeena, "Agricultural Robot for Automatic Ploughing and Seeding," Innovations in ICT for Agricultural and Rural Development TIAR 2015 international conference (IEEEPublication), pp 17-23.

[3] AkhilaGollakota ,M.B. Srinivas “ agribot- A multipurpose agricultural robot”, india conference(INDICON), 2011 Annual IEEE, 1-4,2011.

[4] GulamAmer,G;Mudassir, S.M.M; Malik,M.A., "Design and operation of Wi-Fi Agribot Integrated system," Industrial Instrumentation and Control,(2015) International Conference(IEEE Publication),pp 207-212.

[5] A. A. NippunKumaar; Sudarshan TSB "Mobile Robot Programming by Demonstration", 2011 Fourth International Conference on Emerging Trends in Engineering \& Technology Year: 2011, Pages: 206 - 209.

[6] ParthGargava, Karan Sindhwani, SumitSoman, "Controlling anArduino robot using Brain Computer Interface" International Conference on Reliability, Infocam Technologies and optimization, (2014), pp-1-5.

[7]Swati D. Sambare, S.S.Belsare, "Seed Sowing Using Robotics Technology," International Journal of scientific research and management (IJSRM), 2015, Volume3, Issue5, Pages 2889-2892, ISSN: 2321-3418.

[8] Mark E. Russell, Balaji A, NippunKumaar A A, Sudarshan TSB, "3 axis SCARA robot with universal gripper," 2015 International Conference on Trends in Automation, Communications and Computing Technology (ITACT-15)Year: 2015, Pages: 1-5.
[9] Rabiulhossenrafi, shuva das, nawsherahmed, iftekharhossain, s m taslimreza, "Design and implementation of a line follower robot for irrigations based application."

[10] Lijina. P Amrita; A. A. NippunKumaar, "Bluetooth RSSI based collision avoidance in multirobot environment," 2016 International Conference on Advances in Computing, Communications and Informatics (ICACCI) Year: 2016, Pages: $2168-2174$.

[11] SaurabhUmarkar and Anil Karwankar, "Automated Seed Sowing Agribot using Arduino," Communication and Signal Processing 2016 in international conference (IEEEPublication), pp 1379-1383.

[12] Roberto Oberti, Massimo Marchi, Paolo Tirelli, Aldo Calcante, Marcello Iriti, EmanueleTona, Marko Hočevar, JoergBaur, Julian Pfaff, ChristophSchütz, Heinz Ulbrich "Selective spraying of grapevines for disease control using a modular agricultural robot"Biosystems engineering 146, 203 215,2017

[13] T.A. Mohanaprakash, K. Sujarajeshwais.annie, shreya M, vidhya I. jenitto, "smart agriculture monitaring system based on IoT" IJAICT Volume 4, Issue 11, merch 2018.

[14] Pirkalaathishreddy, G. E. babu, "AGRIBOT -RF based farmer friendly Agricultural Robot with automatic seed dispensing system" international journal of research Volume 7, Issue VII, JULY/2018 issue no.2236-6134.

[15] DasarinagaVinod, Tripatysingh, "autonomous farming and surveillance agribot in adjucent boundary", 9th international conference on computing, communication and networking Technologies (ICCCNT), 1-7, 2018.

[16] www.google.com 